\title{
Universal versus Risk-Based Management of Unknown Group B Streptococcus Status at Term
}

\author{
Danielle M. Jones, $\mathrm{BS}^{1}$ Samantha O. Haikal, $\mathrm{DO}^{2}$ \\ David L. Howard, MD, PhD ${ }^{1,2,4}$ \\ ${ }^{1}$ School of Medicine, University of Nevada, Las Vegas, Las Vegas, \\ Nevada \\ ${ }^{2}$ College of Osteopathic Medicine, Touro University Nevada, \\ Henderson, Nevada \\ ${ }^{3}$ Department of Obstetrics and Gynecology, Baylor College of \\ Medicine, Houston, Texas \\ ${ }^{4}$ Las Vegas Minimally Invasive Surgery and Women's Pelvic Health \\ Center (A Davita Medical Group), Las Vegas, Nevada \\ Am J Perinatol Rep 2019;9:e315-e322.
}

Megan D. Whitham, MD

\begin{abstract}
Address for correspondence David L. Howard, MD, PhD, Las Vegas Minimally Invasive Surgery and Women's Pelvic Health Center (A Davita Medical Group), 9260 W Sunset Road Suite 200, Las Vegas, NV 89148 (e-mail: david.howard@unlv.edu).
\end{abstract}

\author{
Abstract \\ Keywords \\ - early-onset Group B \\ streptococcus \\ (EOGBS) \\ - intrapartum \\ antibiotic prophylaxis \\ - risk-based \\ management of GBS \\ - universal \\ management of GBS \\ - neonatal sepsis \\ - prelabor rupture of \\ membranes \\ - maternal intrapartum \\ fever
}

Objectives This article estimates and compares public health costs of universal versus risk-based intrapartum antibiotic prophylaxis (IAP) administration for women with unknown Group B streptococcus (GBS) status at term.

Study Design The annual number of women in the U.S. who are: unscreened for GBS, without risk factors, delivering vaginally, multiparous, and eligible for discharge within 24 hours was estimated. Under the risk-based strategy, women and neonates were assumed to stay another day for observation and incur the cost of an additional 24-hour stay. With universal IAP administration, women delivering without complications were assumed to be discharged within 24 hours, with an incurred cost of penicillin.

Results The estimated cost for the risk-based management of unscreened women at term without rupture of membranes (ROM) $>18$ hours ranged from $\$ 468,886,831$ to $\$ 850,556,179$. Similarly, the cost of managing unscreened women without maternal intrapartum fever (MIF) ranged from $\$ 742,024,791$ to $\$ 919,269,233$. Alternatively, universal IAP administration costs ranged from $\$ 470,107,674$ to $\$ 568,359,086.5$. Cost comparisons yielded an equivalence or up to a $33.2 \%$ reduction in cost, and 36.6 to $38.2 \%$ reduction in cost for women without ROM $>18$ hours and MIF, respectively.

Conclusions Universal IAP may be cost saving due to the reduction in extended hospitalizations for neonates and healthy mothers.
Since its emergence in the 1970 s as a prominent infectious cause of mortality and morbidity in neonates, ${ }^{1-4}$ maternal colonization of Group B streptococcus (GBS) remains a frequent cause of secondary sequelae, including sepsis, pneumonia, and meningitis. ${ }^{2,5,6}$ The current recommended strategy for management of GBS colonization is selective intrapartum antibiotic prophylaxis (IAP) for screen-positive mothers, following a universal antepartum rectovaginal culture at 35 to 37 weeks' gestation and for women with risk factors for GBS transmission to the infant. ${ }^{1,7}$ This strategy has been shown to be effective in decreasing the incidence of GBS colonization in infants and preventing early-onset GBS (EOGBS)-related illness, which is defined as disease onset before the 7th day of life. ${ }^{1,5,8}$ Since the implementation of universal antepartum screening and the use of IAP for GBS management, the incidence of EOGBS is currently reported at an all-time low of between 0.23 and $0.37 / 1,000$ births in the United States. ${ }^{9}$ Current cases of EOGBS are uncommon in patients who received

March 18, 2019 accepted after revision May 14, 2019
DOI https://doi.org/

10.1055/s-0039-1695744. ISSN 2157-6998.
Copyright $\odot 2019$ by Thieme Medical Publishers, Inc., 333 Seventh Avenue, New York, NY 10001, USA. Tel: +1(212) 584-4662.
License terms

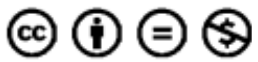


e316 Universal versus Risk-Based Management of Unknown Group B Streptococcus Status at Term Jones et al.

Table 1 Economic costs of hospitalization for women without ROM > 18 hours at term who do not receive intrapartum antibiotic prophylaxis (IAP)

\begin{tabular}{|l|l|l|}
\hline Population & Calculation & Results \\
\hline \# of births in the U.S. in 2016 & & $3,877,317^{16}$ \\
\hline \# of births to women at term with GBS unknown status & $n \times 10.7 \%^{14}$ & 414,873 \\
\hline \# Women without PROM & $n \times\left(61.8 \%^{10}-91.6 \%^{11}\right)$ & $256,391-380,024$ \\
\hline \# Women that deliver vaginally & $n \times 68.1 \%^{\text {a }}$ & $174603-258,796$ \\
\hline \# Women from this population that are multiparous & $n \times\left(47.8 \%^{4}-58.5 \%^{14}\right)$ & $83,460-151,396$ \\
\hline Cost of a 48-h hospitalization for this population WITHOUT IAP & $n \times \$ 5,618.1^{\text {b }}$ & $\$ 468,886,831-\$ 850,556,179$ \\
\hline
\end{tabular}

Abbreviations: GBS, Group B streptococcus; PROM, premature rupture of membranes; ROM, rupture of membranes.

${ }^{a}$ Inferred estimated of number of women that deliver vaginally based on cited estimate of $31.9 \%{ }^{15,17,19,36}$ of women that deliver via cesarean section.

${ }^{\mathrm{b}}$ - Table 5 shows the calculations used to determine the cost of a 24- and 48-hour hospitalization used in these calculations.

screened positive during their antenatal course and who received adequate IAP; cases of sepsis can be attributed to the transient nature of GBS infection (culture-negative patients in the antenatal course who then go on to deliver infected neonates) and untreated, unscreened mothers for whom GBS colonization had not been determined before labor and for whom IAP was not administered. ${ }^{4,10,11}$

Currently, women with unknown GBS statuses who are at least 37 weeks' gestational age and who have no risk factors are not recommended to receive IAP. ${ }^{1,7}$ On the pediatric side, babies born to these women who are GBS positive or GBS status unknown at term and who did not receive IAP are observed for up to 48 hours following delivery. ${ }^{2,12}$ Therefore, with respect to unknown GBS status at term, there appears to be a conflict between the bodies governing obstetrics and gynecology versus pediatrics. To address this conflict, the primary aim of this study was to compare two strategies for the management of unknown GBS status at term in women without risk factors. The first strategy is the current American College of Obstetrics and Gynecologists' (ACOG) recommended strategy of withholding IAP for women with unknown culture status unless the patient has specific risk factors. ${ }^{1}$ The second strategy is to give IAP regardless of the presence or absence of risk factors, based on the recommendation that the lack of antibiotics during labor will result in infant hospitalizations for the currently recommended 48-hour observation period. Our focus was exclusively on the economic cost to society associated with each strategy.

\section{Methods}

This study was an economic analysis that aimed to compare two strategies for managing women with unknown GBS status at term without risk factors. Our methodology for determining the cost of not administering IAP because of the current riskbased administration of prophylaxis for the management of unknown GBS status at term is outlined in - Tables $\mathbf{1}$ and $\mathbf{2}$ for women presenting without prolonged rupture of membranes (ROM) and maternal intrapartum fever (MIF), respectively. These clinical schemas were chosen because they are the most frequently encountered exclusionary criteria for withholding antibiotics in labor and employing the risk-based strategy; thus, patients with prolonged ROM or MIF would receive IAP. Our methodology for determining the cost of managing GBS status unknown at term with universal prophylaxis is outlined in -Table 3. The prior publications used to obtain the data needed for our cost estimates are displayed in - Table 4.

We performed a limited sensitivity analysis to estimate the public health costs for the universal and risk-based strategies of GBS management by determining the minimum, average, and maximum incidences of MIF, premature ROM, and multiparity among women. We estimated the

Table 2 Economic costs of hospitalization for women without MIF at term who do not receive intrapartum antibiotic prophylaxis (IAP)

\begin{tabular}{|l|l|l|}
\hline Population & Calculation & Results \\
\hline \# of births in the U.S. in 2016 & & $3,877,317^{16}$ \\
\hline \# of births to women at term with GBS unknown status & $n \times 10.7 \%^{14}$ & 414,873 \\
\hline \# Women without MIF & $n \times\left(97.8^{10}-99 \%^{15}\right)$ & $405,746-410,724$ \\
\hline \# Women that deliver vaginally & $n \times 68.1 \%^{\text {a }}$ & $276,313-279,703$ \\
\hline \# Women that are multiparous & $n \times\left(47.8^{4}-58.5 \%^{14}\right)$ & $132,078-163,626$ \\
\hline Cost of a 48-h hospitalization for this population WITHOUT IAP & $n \times \$ 5,618.1^{\text {b }}$ & $\$ 742,024,791-\$ 919,269,233$ \\
\hline
\end{tabular}

Abbreviations: GBS, Group B streptococcus; MIF, maternal intrapartum fever.

${ }^{a}$ Inferred estimate of number of women that deliver vaginally based on cited estimate of $31.9 \%{ }^{15,17,19,36}$ of women that deliver via cesarean section.

b Table 5 shows the calculations used to determine the cost of a 24- and 48-hour hospitalization used in these calculations. 
Table 3 Economic costs for universal IAP

\begin{tabular}{|c|c|c|c|}
\hline Population & Calculation & Results & \\
\hline \# of births in the U.S. in 2016 & & $3,877,317^{16}$ & \\
\hline \multirow{2}{*}{$\begin{array}{l}\text { \# of births to women at term with GBS } \\
\text { unknown status }\end{array}$} & $n \times 10.7 \%^{14}$ & 414,873 & \\
\hline & $\begin{array}{l}\text { Cost of PCN for all } \\
\text { women during } \\
\text { labor course }\end{array}$ & $\begin{array}{l}\text { \# of births to wom- } \\
\text { en at term with GBS } \\
\text { unknown } \\
\text { status } \times \$ 75.18^{18}\end{array}$ & $\begin{array}{l}\$ 31,190,146 \\
\text { to be added to total } \\
\text { cost of hospitalization }\end{array}$ \\
\hline \# Women that delivery vaginally & $n \times 68.1 \%^{\mathrm{a}}$ & 282,528 & \\
\hline \# Women that are multiparous & $n \times\left(47.8 \%^{4}-58.5 \%^{14}\right)$ & $135,049-165,279$ & \\
\hline \# Women that deliver WITH complications & $n \times 15.7 \%^{19}$ & $21,203-25,949$ & \\
\hline \# Women that deliver WITHOUT complications & $n \times 84.3 \%{ }^{19}$ & $113,846-139,330$ & \\
\hline $\begin{array}{l}\text { Cost of a 48-h hospitalization for women that } \\
\text { deliver WITH complications }\end{array}$ & $n \times \$ 5,618.1^{b}$ & $\begin{array}{l}119,118,499- \\
\$ 145,783,101\end{array}$ & \\
\hline $\begin{array}{l}\text { Cost of a 24-h hospitalization for women that } \\
\text { deliver WITHOUT complications }\end{array}$ & $n \times \$ 2,809.05^{b}$ & $\begin{array}{l}\$ 319,799,028- \\
\$ 391,385,840\end{array}$ & \\
\hline $\begin{array}{l}\text { Total economic costs of hospitalizations when } \\
\text { implementing universal IAP }\end{array}$ & $\begin{array}{l}\text { Sum of costs of } \\
\text { hospitalization \& PCN } \\
\text { for all women during } \\
\text { labor course = }\end{array}$ & $\begin{array}{l}\$ 470,107,673.5- \\
\$ 568,359,087\end{array}$ & \\
\hline
\end{tabular}

Abbreviations: GBS, Group B streptococcus; IAP, intrapartum antibiotic prophylaxis; PCN, penicillin.

anferred estimate of number of women that deliver vaginally based on cited estimate of $31.9 \% 15,17,19,36$ of women that deliver via cesarean section.

b Table 5 shows the calculations used to determine the cost of a 24- and 48-hour hospitalization used in these calculations.

public health costs by grouping incidences for each calculation, such that the minimum incidence values were used to determine the minimum societal cost estimate for both strategies of GBS management. This same method of grouping was used to determine the average and maximum societal cost estimates.

The Consolidated Health Economic Evaluation Reporting Standards checklist for reporting standards was adhered to in the economic analysis. ${ }^{13}$
Van Dyke et al evaluated the efficacy of universal screening and management of GBS in women during pregnancy. In this large study of over 7,000 women, the percentage of women who presented at term with unknown GBS status was $10.7 \%{ }^{14}$ This percentage was used as the basis of all our calculations. We obtained an estimate of the total number of women in the United States with GBS status unknown at term by multiplying $10.7 \%$ by the total number of women who gave birth in 2016. ${ }^{14,15}$

Table 4 Referencing source used for cost estimate calculations

\begin{tabular}{|l|l|}
\hline Data point & Referencing source \\
\hline $\begin{array}{l}\text { \% of women who present at term with Group B } \\
\text { streptococcus status unknown }\end{array}$ & Van Dyke et al (2009) \\
\hline \# of babies born in the United States in 2016 & Martin et al (2018) \\
\hline \% of singleton births in the United States in 2016 & Martin et al (2018) \\
\hline$\%$ of women who present with rupture of membranes $>18$ hours & Zuppa et al (2014) and Gilson et al (2000) \\
\hline$\%$ of women who present with maternal intrapartum fever & Zuppa et al (2014) and Makhoul et al (2007) \\
\hline$\%$ of women who deliver via cesarean section & Pasko et al (2018) and Martin et al (2018) \\
\hline$\%$ of women who are multiparous & Picchiassi et al (2018) and Van Dyke et al (2009) \\
\hline $\begin{array}{l}\text { \% of women who deliver vaginally with complications/ } \\
\text { no complications }\end{array}$ & Podulka et al (2011) \\
\hline Cost of one-night hospitalization for mother & Podulka et al (2011) \\
\hline Cost of one-night hospitalization for infant & Kowlessar et al (2013) \\
\hline Cost of intrapartum antibiotic prophylaxis (penicillin) & Lexicomp (2019) \\
\hline
\end{tabular}




\section{Strategy 1: Determining the Societal Cost of Risk-Based Administration of IAP to Women Who Present at Term with GBS Status Unknown and No Known Risk Factors}

The total population of women who present at term with unknown GBS status was further stratified for the presence or absence of risk factors. As outlined in -Table 1, the percentage of women who present at term without ROM $>18$ hours ranged from $61.8^{10}$ to $91.6 \%{ }^{11}$ in previous studies. As outlined in -Table 2, the percentage of women who present at term without MIF ranged from $97.8^{10}$ to $99 \%^{16}$ in previous studies. These percentages were used to determine the proportion of the total population of women giving birth in the United States annually who would not have been treated based on the current ACOG guidelines.

This population of women untreated for GBS status unknown at term was further stratified based on delivery method. Based on the $31.9 \%$ national cesarean delivery rate, ${ }^{15,17}$ we estimated that the vaginal delivery rate would be $68.1 \%$. According to the current ACOG guidelines, the women who had GBS status unknown at term without risk factors and who delivered vaginally would not qualify for IAP.

The total population of untreated women per ACOG guidelines was analyzed further based on parity, due to an assumption that multiparous women are typically eligible for discharge within 24 hours postpartum. The percentage of multiparous women, based on 1 previous live birth, was determined through an analysis of multiple studies. The percentage of multiparous women ranged from $47.8^{4}$ to $58.5 \%{ }^{14}$ Without IAP, these women, who were multiparous and delivered vaginally with GBS status unknown and no known risk factors at term, would not be discharged within 24 hours and, instead, would incur an additional 24-hour hospitalization while their infant was observed for the potential development of GBS disease. ${ }^{12}$ The cost of a 2-day hospitalization for both mother and infant was applied to this total stratified population of women to estimate the total economic cost of the current risk-based management of GBS status unknown at term without risk factors. To determine the cost of a 48-hour hospitalization, the cost of hospitalization for neonate and postpartum mother were summed and then multiplied by 2 (-Table 5).

\section{Strategy 2: Determining the Societal Cost of Universal Administration of IAP to Women Who Present at Term with Unknown GBS Status}

Strategy 2 assumed that the total population of women who presented at term with unknown GBS status would be prophylactically treated, regardless of the presence or absence of risk factors. The population of women who presented at term with GBS status unknown was assumed to receive penicillin $\mathrm{G}$ at least 4 hours prior to delivery, consistent with the current recommendations for prophylactic treatment of GBS colonization. ${ }^{1,3,5,7}$ We assumed this treatment would include the initial loading dose of 5 million units, with at least 1 subsequent dose of 2.5 million units of penicillin $\mathrm{G}$. The combined cost of the single loading dose and subsequent dose, was estimated by averaging a composite resource reported value of $\$ 37.95$ and multiplying by 2 ( - Table 5), to arrive at an average of $\$ 75.18$ for IAP during labor per patient. ${ }^{18}$ Two doses were chosen in lieu of one dose as $55 \%$ of laboring women will require more than 4 hours of antibiotics, meaning an additional dose would need to be administered in addition to a loading dose to cover

Table 5 Calculations for the estimated values used to further determine the total estimated cost of hospitalization for Strategies 1 and 2

\begin{tabular}{|c|c|c|}
\hline Value & Calculation & Estimated total \\
\hline $\begin{array}{l}\text { Estimated cost of } 24 \mathrm{~h} \text { hospitalization for infant in } \\
2016^{\mathrm{a}}\end{array}$ & $\begin{array}{l}\text { The cost was } \$ 941.176 \text { in } 2011^{36} \text {; with } \\
\text { cumulative inflation of } 6.7 \%,{ }^{37} \text { the cost in } 2016 \\
\text { would be }=\end{array}$ & $\$ 1,004.23$ \\
\hline $\begin{array}{l}\text { Estimated cost of } 24 \mathrm{~h} \text { hospitalization for mother } \\
\text { in } 2016^{\mathrm{b}}\end{array}$ & $\begin{array}{l}\text { The cost was } \$ 1,619.047 \text { in } 2008^{19} \text {; with } \\
\text { cumulative inflation of } 11.5 \%, 37 \text { the cost in } \\
2016 \text { would be }=\end{array}$ & $\$ 1,804.82$ \\
\hline $\begin{array}{l}\text { Estimated cost of } 24 \mathrm{~h} \text { hospitalization for mother } \\
\text { and infant pairs }\end{array}$ & $\$ 1,004.23+\$ 1,804.82$ & $\$ 2,809.05$ \\
\hline Estimated cost of $48 \mathrm{~h}$ hospitalization for infant & $\$ 1,004.23 \times 2$ & $\$ 2,008.46$ \\
\hline Estimated cost of $48 \mathrm{~h}$ hospitalization for mother & $\$ 1,804.82 \times 2$ & $\$ 3,609.64$ \\
\hline $\begin{array}{l}\text { Cost of } 48 \mathrm{~h} \text { hospitalization for mother and infant } \\
\text { pairs }\end{array}$ & $\$ 2,008.46+\$ 3,609.64$ & $\$ 5,618.1$ \\
\hline Average cost of 1 dose of penicillin & $(\$ 33+\$ 42.18)^{18} / 2$ & $\$ 37.59$ \\
\hline Average cost of 2 doses of penicillin & $\$ 37.59 \times 2$ & $\$ 75.18$ \\
\hline
\end{tabular}

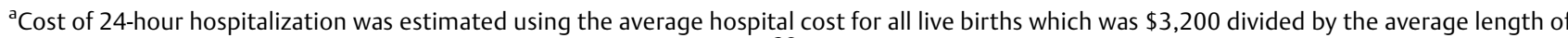
stay (days) of 3.4 to generate an estimate of $\$ 941.176$ per day in $2011 .{ }^{36}$ Costs were further adjusted for inflation to the year 2016 , to standardize dates for birthing statistics and health care costs.

${ }^{b}$ Cost of 24-hour hospitalization was estimated using the mean cost per stay of vaginal delivery without complication of $\$ 3,400$ divided by the mean length of stays (days) of 2.1 to generate an estimate of $\$ 1,619.047$ per day in $2008 .{ }^{19}$ Costs were further adjusted for inflation to the year 2016 , to standardize dates for birthing statistics and health care costs. 
Table 6 Economic cost to society of women who present at term without rupture of membranes $>18$ hours

\begin{tabular}{|l|l|l|l|}
\hline Estimates used in calculations & $\begin{array}{l}\text { Universal cost } \\
\text { of IAP (\$) }\end{array}$ & $\begin{array}{l}\text { Cost of current } \\
\text { standard of care (\$) }\end{array}$ & Variation of cost with IAP (\%) \\
\hline Minimum values of estimates & $470,107,673.5$ & $468,886,831.4$ & $0.25 \%$ cost increase \\
\hline Average values of estimates & $519,233,380$ & $647,068,557.4$ & 19.2 cost reduction \\
\hline Maximum values of estimates & $568,359,086.5$ & $850,556,178.9$ & 33.2 cost reduction \\
\hline
\end{tabular}

Abbreviation: IAP, intrapartum antibiotic prophylaxis.

$4+$ hours. This number was used to estimate the total cost of prophylactically treating the entire population of women who presented with GBS status unknown at term. This cost was added to the total cost of hospitalization for motherinfant pairs postpartum to compare against the estimated total cost of the risk-based management of GBS status unknown at term.

As outlined in - Table 3, the hospitalization costs for Strategy 2 were estimated by further stratifying the total population of women with GBS status unknown at term based on delivery method, complications associated with delivery, and parity. Of women delivering vaginally, we assumed $84.3 \%$ would deliver without complications and, therefore, were eligible for discharge within 24 hours postpartum, while the remaining $15.7 \%$ of women delivering vaginally with complications were assumed to be discharged within 48 hours. ${ }^{19}$ The cost of hospitalization was estimated per mother-infant pairs, based on length of stay, and was then summed to determine the total economic cost of hospitalization for Strategy 2. The total cost of hospitalization was then summed with the cost of penicillin $G$ administration to estimate the total societal economic cost of universal prophylaxis for all women who presented at term with unknown GBS status.

\section{Determining the Cost Reduction of Universal Prophylactic Management versus Risk-Based Prophylactic Management of GBS Status Unknown at Term}

The total economic cost to society of the risk-based management of GBS status unknown at term for women presenting without ROM $>18$ hours or MIF versus universal prophylaxis are compared in -Tables 6 and 7, respectively.

\section{Results}

We estimated the societal cost of universal prophylactic management of GBS status unknown at term to range from
$\$ 470,107,674$ to $\$ 568,359,087$ ( - Table 3 ). The estimated economic cost to society for the risk-based management of women who present at term with GBS status unknown and the absence of ROM $>18$ hours ranged from $\$ 468,886,831$ to $\$ 850,556,179$ ( - Table 1). When these cost estimates were compared with that of the universal IAP for treatment of unknown GBS status, a cost increase of $0.25 \%$ was calculated for the lower end estimate of universal prophylaxis, while a $33.2 \%$ cost reduction was calculated for the higher end of universal prophylaxis (-Table 6).

In addition, the estimated economic cost to society for the risk-based management of women who present at term with GBS status unknown and the absence of MIF ranged from $\$ 742,024,791$ to $\$ 919,269,233$ (-Table 2). When these cost estimates were compared with that of universal prophylaxis, a cost reduction that ranged from 36.6 to $38.2 \%$ was observed (-Table 7).

\section{Discussion}

Appropriate timing of discharge for the healthy term neonate is a delicate balance for the providing pediatrician. One component of this evaluation, given its prevalence and morbidity, is evaluation for EOGBS. Roughly $95 \%$ of infants with invasive GBS disease will present with symptoms within the first 24 hours of life, prior to the earliest anticipated discharge. ${ }^{20}$ A 2012 cost analysis by Berger et al suggests that delayed hospital discharge at 48 hours for women treated with IAP results in similar mean expected quality-adjusted life years (QALYs) but greater mean hospitalization costs, estimated at $\$ 1,170.96 .{ }^{12}$ Currently, early discharge is generally offered to women who deliver vaginally and who receive adequate IAP in labor or to infants born to culture-negative mothers. ${ }^{21}$ Those women with unknown culture status who do not receive IAP are excluded from early discharge, due to a delay period for observation for EOGBS in the neonate, which amounts to considerable potential cost expenditures in maternal and neonatal delayed discharges in a substantial subset of the population. ${ }^{14}$

Table 7 Economic cost to society of women who present at term without maternal intrapartum fever

\begin{tabular}{|l|l|l|l|}
\hline Estimates used in calculations & Universal cost of IAP (\$) & Cost of current standard of care (\$) & $\begin{array}{l}\text { Reduction of } \\
\text { cost with IAP (\%) }\end{array}$ \\
\hline Minimum values of estimates & $470,107,673.5$ & $742,024,791.4$ & 36.6 \\
\hline Average values of estimates & $519,233,380$ & $830,137,497.4$ & 37.5 \\
\hline Maximum values of estimates & $568,359,086.5$ & $919,269,232.7$ & 38.2 \\
\hline
\end{tabular}

Abbreviation: IAP, intrapartum antibiotic prophylaxis. 
In our study, we compare the cost effectiveness of two management strategies for the management of the GBSunknown patient in labor at term: universal IAP versus the current more commonly practiced risk-based IAP. The results suggest a considerable population-based cost savings associated with universal IAP for unscreened women in labor at term, due to decreased need for extended postnatal hospitalization for term infants and their healthy mothers during a period of monitoring for GBS sepsis after delivery. Cost analysis from the independent models yielded equivalence in total costs or up to a reduction in cost by $33.2 \%$ and reduction in costs by 36.6 to $38.2 \%$ for women without ROM $>18$ hours and MIF, respectively.

Thus, we conclude that universal IAP for unscreened patients at term without risk factors may be cost saving due to the reduced need for extended hospitalization for observation of neonates and mothers otherwise meeting criteria for early discharge.

An alternatively proposed strategy to the currently recommended culture-based and risk-based strategy for the GBS unknown patient, is the adoption of rapid intrapartum polymerase chain reaction testing for all patients in labor and the subsequent IAP administration based on such results. ${ }^{22}$ This strategy would also obviate unnecessary prolonged hospitalization for GBS observation periods for healthy neonates born to healthy term women; however, the major drawbacks include test processing of nearly an hour, inability to test for clindamycin resistance for penicillin allergic patients, and furthermore, high costs associated with the tests at this time.

Cost savings aside, risk-based prophylaxis may be insufficient or inadequate in the GBS-unknown population, and this population remains at risk. Neonatal GBS sepsis cases today remain most common in term infants, despite the 2002 recommendation for universal GBS screening, ${ }^{14,23}$ and the 2009 study by Van Dyke et al suggests that patients with unknown GBS status account for $13.4 \%$ GBS disease at term. Universal IAP for these patients may result in further reductions in early neonatal sepsis cases, particularly given known efficacy of chemoprophylaxis at reducing attack rate of EOGBS by 80 to $95 \%{ }^{24,25}$

The Centers for Disease Control and Prevention published 2000 to 2006 data for EOGBS disease burden within the United States and 178 cases of EOGBS were recorded in 2006 from a population of 450,000 reported the year before ( $11 \%$ of the national population). ${ }^{26}$ This leads to an estimated 1,614 cases per year within the U.S. population at that time, $72 \%$ of cases which occurred in term neonates. ${ }^{26}$ GBS status was known for $93 \%$ patients with babies resulting in EOGBS. This leaves a calculated 81 patients that year in the U.S. population for whom GBS would have been unknown who would otherwise not have received IAP under the currently recommended guidelines for whom therapy may have been beneficial in preventing EOGBS.

IAP for a larger, unscreened population is not without potential risks. Hypersensitivity reactions still remain an important cause of adverse reactions with penicillin therapy.
A cited 5 to $10 \%$ of patients experience a reaction to penicillin treatment. ${ }^{27}$ Anaphylaxis is the most severe manifestation of these hypersensitivity reactions, seen in $1-5 / 10,000$ cases $^{28}$ and can lead to cardiovascular collapse, laryngeal edema, and, rarely, death. IAP would expose an additional 414,873 unscreened individuals to these potential hypersensitivity reactions. Patients with a low risk for anaphylaxis can receive cefazolin for the management of GBS colonization, while patients with a high risk for anaphylaxis can receive vancomycin or clindamycin for GBS colonization management depending on culture sensitivies. ${ }^{29}$ Public health cost estimates for the prophylactic management of GBS colonization with cefazolin, vancomycin, and clindamycin were not included in our analysis, because the cost of cefazolin, vancomycin, and clindamycin is $\$ 0.11,{ }^{30} \$ 0.32,{ }^{31}$ and $\$ 0.31,{ }^{32}$ respectively, for the initial dose of prophylactic management. ${ }^{29}$ Such antibiotic costs are markedly reduced in comparison to penicillin. Additionally, as the percentage breakdown of penicillin-allergic patients using each respective agent is unknown, an estimate to reflect each cost scenario is not technically feasible. Instead, we have chosen penicillin as an upper limit estimate of cost for universal prophylaxis.

An additional risk with more widespread administration of IAP, is a potential to increase multidrug resistance to penicillins. Already, GBS has demonstrated resistance to aminoglycosides, macrolides, and fluoroquinolones. ${ }^{33}$ Along these lines, some studies have suggested an association between exposure to IAP and non-GBS sepsis, or infection with Gram-negative pathogens, and ampicillin-resistant Escherichia coli infection. ${ }^{34,35}$ Given these considerations, universal administration of penicillin during labor to facilitate early discharge should be deferred until appropriate recommendations from governing bodies.

Our study was limited by the body of evidence available to guide recommendations about the early discharge of mother and baby at 24 hours after routine vaginal delivery; the majority of these studies on early discharge are based on noninferiority and do suggest that further randomized control trials would be beneficial to guide clinical recommendations. However, our study aligns with a prior economic analysis by Berger et al that suggests a financial benefit and noninferior practice, as measured by similar QALYs in favor of early discharge for neonates and mothers without evidence of GBS infection in the event of uncomplicated delivery.

In addition, our study was also limited by the number of prior publications focused on unknown GBS status management in the United States. This resulted in data obtained from study populations of varying countries being used to estimate the cost of GBS management in the United States. Lastly, we acknowledge a slight underestimation in the total number of women who present at term with unknown GBS status. This underestimation is the result of the categorization of 31 births in 2016 in the United States ${ }^{15}$ being coupled as quintuplet and higher-order pregnancies, which prevented the determination of the exact number of mothers for these births. 


\section{Conclusion}

In conclusion, IAP for the unscreened population may allow for early discharge of otherwise healthy mother and baby, as the time needed for in-house GBS sepsis observation would be eliminated. On a population scale, this would allow for a significant decrease in health care costs, when compared with the currently employed risk-based prophylaxis algorithm. Thus, our recommendation would be to begin implementation of routine IAP for patients with uncomplicated pregnancies and who are GBS culture-unknown at term without contraindications to prophylaxis.

\section{Financial Disclosure}

The authors have no financial relationships relevant to this article to disclose.

\section{Funding}

No funding was secured for this study.

\section{Conflict of Interest}

The authors have no conflicts of interest.

\section{Acknowledgment}

The authors thank Jasmine L. Hankey for her editorial assistance in the preparation of this manuscript.

\section{References}

1 American College of Obstetricians and Gynecologists Committee on Obstetric Practice. ACOG Committee Opinion No. 485: prevention of early-onset group B streptococcal disease in newborns. Obstet Gynecol 2011;117(04):1019-1027

2 Verani JR, McGee L, Schrag SJ; Division of Bacterial Diseases, National Center for Immunization and Respiratory Diseases, Centers for Disease Control and Prevention (CDC). Prevention of perinatal group B streptococcal disease-revised guidelines from CDC, 2010. MMWR Recomm Rep 2010;59(RR-10):1-36

3 Baker CJ, Byington CL, Polin RA; Committee on Infectious Diseases; Committee on Fetus and Newborn. Policy statementrecommendations for the prevention of perinatal group B streptococcal (GBS) disease. Pediatrics 2011;128(03):611-616

4 Picchiassi E, Coata G, Babucci G, et al. Intrapartum test for detection of Group B Streptococcus colonization during labor. J Matern Fetal Neonatal Med 2018;31(24):3293-3300

5 Barber EL, Funai EF, Bracken MB, Illuzzi JL. Interpretation of 2002 Centers for Disease Control guidelines for group B streptococcus and evolving provider practice patterns. Am J Perinatol 2011;28 (02):97-102

6 Cheng PJ, Chueh HY, Liu CM, Hsu JJ, Hsieh TT, Soong YK. Risk factors for recurrence of group B streptococcus colonization in a subsequent pregnancy. Obstet Gynecol 2008;111(03):704-709

7 Apgar BS, Greenberg G, Yen G. Prevention of group B streptococcal disease in the newborn. Am Fam Physician 2005;71(05):903-910

8 Tam T, Bilinski E, Lombard E. Recolonization of group B Streptococcus (GBS) in women with prior GBS genital colonization in pregnancy. J Matern Fetal Neonatal Med 2012;25(10):1987-1989

9 Nanduri SA, Petit S, Smelser C, et al. Epidemiology of invasive early-onset and late-onset Group B streptococcal disease in the United States, 2006 to 2015: multistate laboratory and population-based surveillance. JAMA Pediatr 2019;173(03):. Doi: $10.1001 /$ jamapediatrics.2018.4826
10 Zuppa AA, Alighieri G, Fracchiolla A, et al. Effectiveness of a prematurity-based protocol for management of infants born to mothers with Group B Streptococcus colonisation. JObstet Gynaecol 2014;34(08):673-678

11 Gilson GJ, Christensen F, Romero H, Bekes K, Silva L, Qualls CR. Prevention of group B streptococcus early-onset neonatal sepsis: comparison of the Center for Disease Control and prevention screening-based protocol to a risk-based protocol in infants at greater than 37 weeks' gestation. JPerinatol 2000;20(8 Pt 1):491-495

12 Berger MB, Xu X, Williams JA, Van de Ven CJ, Mozurkewich EL. Early hospital discharge of infants born to group B streptococcipositive mothers: a decision analysis. BJOG 2012;119(04): 439-448

13 Husereau D, Drummond M, Petrou S, et al; ISPOR Health Economic Evaluation Publication Guidelines-CHEERS Good Reporting Practices Task Force. Consolidated Health Economic Evaluation Reporting Standards (CHEERS)-explanation and elaboration: a report of the ISPOR Health Economic Evaluations Publication Guidelines Good Reporting Practices Task Force. Value Health 2013;16(02):231-250

14 Van Dyke MK, Phares CR, Lynfield R, et al. Evaluation of universal antenatal screening for group B streptococcus. N Engl J Med 2009; 360(25):2626-2636

15 Martin JA, Hamilton BE, Osterman MJK, Driscoll AK, Drake P. Births: final data for 2016. Natl Vital Stat Rep 2018;67(01):1-55

16 Makhoul IR, Sprecher H, Smolkin T, et al. Approach to term neonates born after maternal intrapartum fever and unknown maternal group B Streptococcus status: value of serum C-reactive protein and 16S rRNA gene PCR amplification. Pediatr Infect Dis J 2007;26(11):1064-1066

17 Pasko DN, McGee P, Grobman WA, et al; Eunice Kennedy Shriver National Institute of Child Health and Human Development (NICHD) Maternal-Fetal Medicine Units (MFMU) Network. Variation in the nulliparous, term, singleton, vertex cesarean delivery rate. Obstet Gynecol 2018;131(06):1039-1048

18 Lexicomp. 2019. Penicillin G (intravenous and short-acting intramuscular): Drug information. Lexicomp, UpToDate. Available at: https://www-uptodate-com.ezproxy.library.unlv.edu/contents/ penicillin-g-intravenous-and-short-acting-intramuscular-druginformation?search=U.S.\%20 cost\%20of\%20penicillin\%20G\&source=search_result\&selectedTitle=7 150\&usage_type=default\&display_rank=7\#F16323647. Accessed April 14, 2019

19 Podulka J, Stranges E, Steiner C Hospitalizations Related to Childbirth, 2008: Statistical Brief \#110. Healthcare Cost and Utilization Project (HCUP) Statistical Briefs. Rockville, MD: Agency for Healthcare Research and Quality (US); 2006-2011 April

20 Bromberger P, Lawrence JM, Braun D, Saunders B, Contreras R, Petitti DB. The influence of intrapartum antibiotics on the clinical spectrum of early-onset group B streptococcal infection in term infants. Pediatrics 2000;106(2 Pt 1):244-250

21 Benahmed N, San Miguel L, Devos C, Fairon N, Christiaens W. Vaginal delivery: how does early hospital discharge affect mother and child outcomes? A systematic literature review. BMC Pregnancy Childbirth 2017;17(01):289

22 Di Renzo GC, Melin P, Berardi A, et al. Intrapartum GBS screening and antibiotic prophylaxis: a European consensus conference. J Matern Fetal Neonatal Med 2015;28(07):766-782

23 Pulver LS, Hopfenbeck MM, Young PC, et al. Continued early onset group B streptococcal infections in the era of intrapartum prophylaxis. J Perinatol 2009;29(01):20-25. Doi: 10.1038/jp.2008

24 Smaill FM. Intrapartum antibiotics for Group B streptococcal colonisation. Cochrane Database Syst Rev 2004;(03):CD000115

25 Benitz WE, Gould JB, Druzin ML. Antimicrobial prevention of early-onset group B streptococcal sepsis: estimates of risk reduction based on a critical literature review. Pediatrics 1999;103(06): e78 
26 Centers for Disease Control and Prevention (CDC). Trends in perinatal group B streptococcal disease - United States, 2000-2006. MMWR Morb Mortal Wkly Rep 2009;58(05): 109-112

27 Solensky R. Penicillin allergy: immediate reactions. In: Feldweg AM, ed. UpToDate. 2019. Available at: https://www-uptodatecom.ezproxy.library.unlv.edu/contents/penicillin-allergy-immediate-reactions? search=cost $\% 20$ of $\% 20$ penicillin $\% 20$ admin $\% 20$ to $\%$ 20prevent\%20EOGBS\&topicRef=438\&source=see_link. Accessed April 15, 2019

28 Bhattacharya S. The facts about penicillin allergy: a review. J Adv Pharm Technol Res 2010;1(01):11-17

29 Baker CJ. Neonatal group B streptococcal disease: prevention. In: Barss VA, ed. UpToDate. 2019. Available at: https://www-uptodate-com.ezproxy.library.unlv.edu/contents/neonatal-group-bstreptococcal-disease-prevention?search=cost\%20of\%20penicillin\%20used\%20in\%20EOGBS\&source=search_result\&selectedTitle=18 150\&usage_type=default\&display_rank=18\#H13. Accessed April 15, 2019

30 Lexicomp. Cefazolin: Drug Information. Lexicomp, UpToDate. 2019. Available at: https://www-uptodate-com.ezproxy.library. unlv.edu/contents/cefazolin-drug-information?search=united\% 20states\%20cost\%20of\%20cefazolin\%20lexicomp\&source=search_result\&selectedTitle=6 150\&usage_type=default\&display_rank=6\#F16323045. Accessed April 15, 2019
31 Lexicomp. Vancomycin: Drug information. Lexicomp, UpToDate. 2019. Available at: https://www-uptodate-com.ezproxy.library. unlv.edu/contents/vancomycin-drug-information\#F233317. Accessed April 15, 2019

32 Lexicomp. Clindamycin (systemic): Drug information. Lexicomp, UpToDate. 2019. Available at: https://www-uptodate-com.ezproxy library.unlv.edu/contents/clindamycin-systemic-drug-information\# F8008170. Accessed April 16, 2019

33 Hays C, Louis M, Plainvert C, et al. Changing epidemiology of Group B streptococcus susceptibility to fluoroquinolones and aminoglycosides in France. Antimicrob Agents Chemother 2016;60(12):7424-7430

34 Bizzarro MJ, Dembry LM, Baltimore RS, Gallagher PG. Changing patterns in neonatal Escherichia coli sepsis and ampicillin resistance in the era of intrapartum antibiotic prophylaxis. Pediatrics 2008;121(04):689-696

35 Schuchat A, Zywicki SS, Dinsmoor MJ, et al. Risk factors and opportunities for prevention of early-onset neonatal sepsis: a multicenter case-control study. Pediatrics 2000;105(1 Pt 1):21-26

36 Kowlessar N, Jiang H, Steiner C. Hospital Stays for Newborns, 2011: Statistical Brief \#163-Healthcare Cost and Utilization Project (HCUP) Statistical Briefs. Rockville, MD: Agency for Healthcare Research and Quality (US); 2006-2013

37 Coin News Media Group LLC. US Inflation Calculator. Available at: https://www.usinflationcalculator.com. Accessed April 14, 2019 